Check for updates

Cite this: RSC Adv., 2017, 7, 40549

Received 20th June 2017

Accepted 4th August 2017

DOI: $10.1039 / \mathrm{c} 7 \mathrm{ra06869g}$

rsc.li/rsc-advances

\section{The influence of charge compensation defects on the spectroscopic properties of europium doped $\mathrm{Ca}_{9} \mathrm{Y}\left(\mathrm{PO}_{4}\right)_{7}$}

\author{
N. Górecka, ${ }^{* a}$ K. Szczodrowski, (D) ${ }^{* a}$ A. Lazarowska, ${ }^{a}$ J. Barzowska, ${ }^{a}$ D. Michalik ${ }^{b}$ \\ and M. Grinberg ${ }^{a}$
}

In this study, a series of $\mathrm{Ca}_{9} \mathrm{Y}\left(\mathrm{PO}_{4}\right)_{7}$ compounds doped with $5 \%$ of Eu ions and with different [Y]/[Ca] ratios was synthesized using the Pechini method. Due to the presence of two different cations in the studied matrix $\left(\mathrm{Ca}^{2+}\right.$ and $\left.\mathrm{Y}^{3+}\right)$ that are available for europium substitution, the synthesis parameters were selected to obtain the incorporation of the europium ions $(5 \% \mathrm{~mol})$ into the calcium sites only. The phase composition as well as elemental analysis and the spectroscopic measurements, carried out before and/or after the reduction of $\mathrm{Eu}^{3+}$ were performed to characterize the obtained phosphors. The XRD patterns show that in all cases the obtained materials consist of pure phase of $\mathrm{Ca}_{9} \mathrm{Y}\left(\mathrm{PO}_{4}\right)_{7}$. PLE and $\mathrm{PL}$ spectra measured before the reduction indicate that for the materials with the excess of yttrium, an additional $\mathrm{Eu}^{3+}$ site is observed which was not observed for materials with a deficiency of yttrium. For samples obtained after the reduction, the luminescence of $\mathrm{Eu}^{2+}$ depends on the changes of the $\mathrm{Y} / \mathrm{Ca}$ ratio. The observed differences in $\mathrm{Eu}^{2+}$ luminescence are discussed taking into account the creation of different compensation defects depending on change of the $\mathrm{Y} / \mathrm{Ca}$ ratio.

\section{Introduction}

Recently, white light emitting diodes (w-LED) have become a very popular source of light. They are characterized by high efficiency, long lifetime and environmental friendliness. There are several methods that are used to obtain white LEDs. One of the methods consists of a combination of a near-UV LED with red, green and blue phosphors. This method is very appealing because of the great colour rendering index of obtained materials and lower production cost. Thus, the investigations on tricolour phosphors which are suitable for excitation at the near UV-region receive great attention because of their important applications in lighting. Selection of a host that can be activated by different ions emitting in different regions of the spectrum is a very important part of LED design. The widely studied hosts of phosphors are based on borates, phosphates, aluminates, silicates, vanadates, etc. $^{\mathbf{1 - 6}}$ Among them, phosphates have been paid intense attention due to their excellent properties. ${ }^{7}$ One of the promising materials in phosphates family is $\mathrm{Ca}_{9} \mathrm{Y}\left(\mathrm{PO}_{4}\right)_{7}$, which has two different cations $\left(\mathrm{Ca}^{2+}\right.$ and $\left.\mathrm{Y}^{3+}\right)$ that are available for lanthanides substitution. ${ }^{8-11}$ This material doped with $\mathrm{Eu}^{2+}$ and $\mathrm{Eu}^{3+}$ ions simultaneously consists of two components that

${ }^{a}$ Institute of Experimental Physics, Faculty of Mathematic, Physics and Informatics, Gdańsk University, Wita Stwosza 57, Gdańsk, Poland. E-mail: fizks@ug.edu.pl; natalia.gorecka@ug.edu.pl

${ }^{b}$ Silesian University of Technology, Department of Materials Science, Krasinskiego 8, 40-019 Katowice, Poland are essential to achieve the emission of white light. $\mathrm{Ca}_{9} \mathrm{Y}\left(\mathrm{PO}_{4}\right)_{7}$ belongs to the whitlockite family and can be described by the general formula: $\mathrm{Ca}_{9} \mathrm{R}\left(\mathrm{PO}_{4}\right)_{7}$, where $\mathrm{R}=\mathrm{Ln}, \mathrm{Pr}, \mathrm{Eu}, \mathrm{Tb}$, Dy, Ho, Er, Y, Bi, Al, Lu. ${ }^{12-18}$

The structural model of $\mathrm{Ca}_{9} \mathrm{Y}\left(\mathrm{PO}_{4}\right)_{7}$ was proposed by Golubev and Lazoryak $^{\mathbf{1 9}}$ and the representation of the unit cell and coordination of the cation sites in $\mathrm{Ca}_{9} \mathrm{Y}\left(\mathrm{PO}_{4}\right)_{7}$ are shown in Fig. 1 and 2, respectively. ${ }^{13,14,17,20}$

Because the crystallographic structure of $\mathrm{Ca}_{9} \mathrm{Y}\left(\mathrm{PO}_{4}\right)_{7}$ is isostructural to the $\beta-\mathrm{Ca}_{3}\left(\mathrm{PO}_{4}\right)_{2}$, the cation sites in $\mathrm{Ca}_{9} \mathrm{Y}\left(\mathrm{PO}_{4}\right)_{7}$ are usually defined in basis of structure of $\mathrm{Ca}_{3}\left(\mathrm{PO}_{4}\right)_{2} \cdot{ }^{13,15}$ The crystal lattice of $\beta-\mathrm{Ca}_{3}\left(\mathrm{PO}_{4}\right)_{2}$ has five different cation sites: seven coordinated $\mathrm{Ca}(1)$ positions, eight coordinated $\mathrm{Ca}(2)$ and $\mathrm{Ca}(3)$ positions, three coordinated $\mathrm{Ca}(4)$ positions, which are statistically half occupied by the $\mathrm{Ca}^{2+}$ ions and half empty (cation vacancies), and the six coordinated $\mathrm{Ca}(5)$ positions, distorted

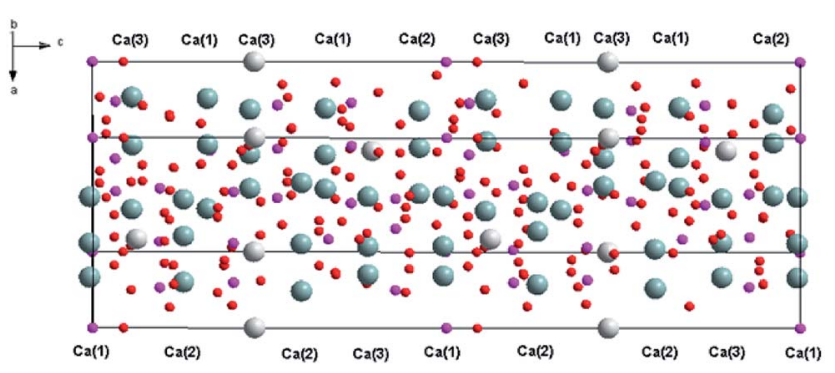

Fig. 1 Representation of the $\mathrm{Ca} 9 \mathrm{Y}\left(\mathrm{PO}_{4}\right)_{7}$ supercell. 

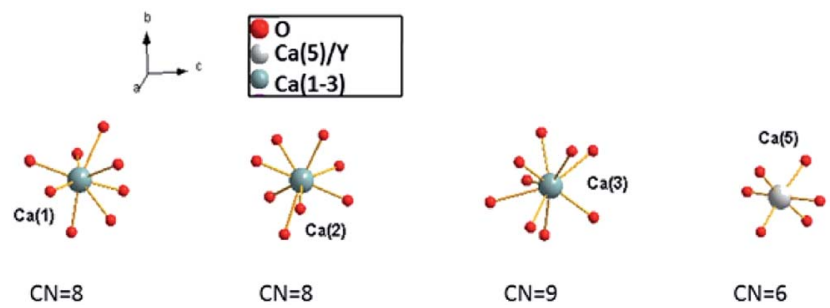

Fig. 2 Coordination of $\mathrm{Ca}(1), \mathrm{Ca}(2), \mathrm{Ca}(3)$ and $\mathrm{Ca}(5) / \mathrm{Y}$ sites.

octahedral sites, fully occupied by $\mathrm{Ca}^{2+}$ ions. ${ }^{21,22}$ Similar situation can be found in $\mathrm{Ca}_{9} \mathrm{Y}\left(\mathrm{PO}_{4}\right)_{7}$ with exception that $\mathrm{Ca}(3)$ site is nine coordinated, $\mathrm{Ca}(5)$ sites are occupied by the $\mathrm{Y}^{3+}$ ions and all $\mathrm{Ca}(4)$ sites are empty (due to the charge imbalance of $\mathrm{Ca}^{2+}$ $\mathrm{Y}^{3+}$ substitution in $\left.\mathrm{Ca}(5)\right)$. The substitution of $\mathrm{Ca}^{2+}$ by the $\mathrm{Y}^{3+}$ ions in $\mathrm{Ca}(5)$ sites does not change the space group of the crystallographic structure and $\mathrm{Ca}_{9} \mathrm{Y}\left(\mathrm{PO}_{4}\right)_{7}$ crystallizes in the trigonal $R 3 c$ (161) space group as in the case of $\mathrm{Ca}_{3}\left(\mathrm{PO}_{4}\right)_{2}$. Independently of the coordination number, the $\mathrm{Ca}(1), \mathrm{Ca}(2)$, $\mathrm{Ca}(3)$ sites are characterized by the $C_{1}$ point symmetry, whereas the point symmetry of $\mathrm{Ca}(5)$ site is $C_{3}$. The values of $\mathrm{Ca}_{9} \mathrm{Y}_{\left(\mathrm{PO}_{4}\right)_{7}}$ lattice parameters are as follows: $a=10.4442 \AA, c=37.324 \AA$, $V=3525.89 \AA^{3}, Z=6 .^{12}$

This paper describes the synthesis, structural properties and the effect of substitution of calcium by europium ions. The main objectives are focused on the investigation of the relations between the material content (the Y/Ca ratio), compensation of the $\mathrm{Eu}^{3+}$ ions in the $\mathrm{Ca}^{2+}$ sites and the efficiency of the reduction process of the $\mathrm{Eu}^{3+}$. To our best knowledge, although the $\mathrm{Ca}_{9}-$ $\mathrm{Y}\left(\mathrm{PO}_{4}\right)_{7}: \mathrm{Eu}^{3+}$ material is known, there are no published papers regarding the spectral properties of $\mathrm{Ca}_{9} \mathrm{Y}\left(\mathrm{PO}_{4}\right)_{7}: \mathrm{Eu}^{3+}, \mathrm{Eu}^{2+}$.

\section{Experimental}

Polycrystalline samples of europium doped $\mathrm{Ca}_{9} \mathrm{Y}\left(\mathrm{PO}_{4}\right)_{7}$ with different $\mathrm{Y} / \mathrm{Ca}$ concentration ratio were synthesized by Pechini method, which is described in details elsewhere. ${ }^{13,23-26}$ The $5 \mathrm{~mol} \%$ of europium was substituted into the calcium sites in all cases. To obtain the desired phosphate, the following reagents were used: $\mathrm{Ca}\left(\mathrm{NO}_{3}\right)_{2} \cdot 4 \mathrm{H}_{2} \mathrm{O}$ ( $\geq 99 \%$ Sigma-Aldrich), $\mathrm{Y}\left(\mathrm{NO}_{3}\right)_{3} \cdot 4 \mathrm{H}_{2} \mathrm{O}(99.999 \%$ Sigma-Aldrich), $\left(\mathrm{NH}_{4}\right)_{2} \mathrm{HPO}_{4} \quad(\geq 99.99 \%$ Sigma-Aldrich $)$, and $\mathrm{Eu}\left(\mathrm{NO}_{3}\right)_{3} \cdot 5 \mathrm{H}_{2} \mathrm{O} \quad(99.9 \%$ Sigma-Aldrich), citric acid (Avantor Performance Materials Poland S.A.) and ethylene glycol (Chempur).

At first, the citric acid was dissolved in distilled water and the ethylene glycol in the appropriate amount was added to the acid solution (the fixed molar ratio of citric acid and ethylene glycol to total chelate metal cations was $5: 1){ }^{23}$ Then the calcium, yttrium and europium nitrates dissolved in distilled water were added to the obtained acid-glycol solution. During the addition of the reagents, the mixture was subsequently stirred. Finally the aqueous solution of $\left(\mathrm{NH}_{4}\right)_{2} \mathrm{HPO}_{4}$ was added to the mixture of all substrates. The resulting solution was heated under reflux for about 1 hour and then the excess of solvent was evaporated at $100{ }^{\circ} \mathrm{C}$. Next, the prepared polyester was dried in the temp. of $80^{\circ} \mathrm{C}$ for $12 \mathrm{~h}$. After drying, the obtained product was calcined

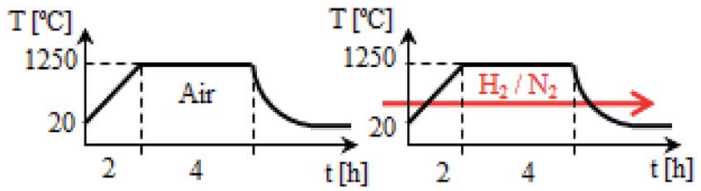

Fig. 3 Scheme of the two-step synthesis.

at $1250{ }^{\circ} \mathrm{C}$ for $4 \mathrm{~h}$ under inert gas atmosphere in the muffle furnace (LHT 04-17, NABERTHERM). Then, the product was cooled, grounded and again calcined at $1250{ }^{\circ} \mathrm{C}$ for $4 \mathrm{~h}$ in a reducing atmosphere, using a mixture of hydrogen ( $5 \mathrm{vol} \%)$ and nitrogen (95 vol\%) in an electrical tubular furnace (PRS $75 \mathrm{WM}$, CZYLOK). The scheme of calcination procedure is shown in Fig. 3. In this way materials: $\mathrm{Ca}_{9.45} \mathrm{Eu}_{0.05} \mathrm{Y}_{0.5}\left(\mathrm{PO}_{4}\right)_{7}$ (denoted as $\mathrm{Y} 0.5$ ), $\mathrm{Ca}_{9.2} \mathrm{Eu}_{0.05} \mathrm{Y}_{0.75}\left(\mathrm{PO}_{4}\right)_{7}$ (Y0.75), $\mathrm{Ca}_{8.95} \mathrm{Eu}_{0.05^{-}}$ $\mathrm{Y}_{1}\left(\mathrm{PO}_{4}\right)_{7}(\mathrm{Y} 1), \mathrm{Ca}_{8.45} \mathrm{Eu}_{0.05} \mathrm{Y}_{1.5}\left(\mathrm{PO}_{4}\right)_{7}(\mathrm{Y} 1.5)$ and $\mathrm{Ca}_{7.95} \mathrm{Eu}_{0.05} \mathrm{Y}_{2}$ $\left(\mathrm{PO}_{4}\right)_{7}(\mathrm{Y} 2)$ were obtained.

The phase purity of all samples was precisely confirmed using powder X-ray diffraction (XRD) measurements (BRUKER D2PHASER) at the rate of $0.02^{\circ}$ and counting time $0.4 \mathrm{~s}$ per step in the $2 \theta$ range from $20^{\circ}$ to $70^{\circ}$, with $\mathrm{Cu} \mathrm{K} \alpha(\mathrm{K} \alpha: 1.54 \AA)$ operating at $30 \mathrm{kV} / 10 \mathrm{~mA}$. Luminescence excitation spectra were measured using the Horiba spectrofluorometer (FluoroMax-4P TCSPC) equipped with $150 \mathrm{~W}$ xenon lamp and R928 Hamamatsu PMT. Photoluminescence spectra were acquired using Shamrock SR750 D1 grating spectrometer followed by iDus 420 CCD detector (Andor Technology) and the CW He-Cd laser was used as an excitation source. All spectra were carefully corrected taking into account the instrumental response function. Time resolved emission spectroscopy of the samples was performed on an experimental setup consisting of tunable parametric light source PG401/SH pumped by 30 ps pulse YAG:Nd PL laser 2143 $\mathrm{A} / \mathrm{SS}$ (Ekspla) and 2501S grating spectrometer (Brucker Optics) coupled to C4334-01 streak camera (Hamamatsu) which acquires streak images with the resolution of $640 \times 480$ points (spectral $\times$ temporal). The time ranges available for a measurement span from $10 \mathrm{~ms}$ down to $1 \mathrm{~ns}^{27}$

Elemental analysis was carried out by a Hitachi S-3400N scanning electron microscope (SEM) operated at $25 \mathrm{kV}$, equipped with an energy-dispersive X-ray Thermo Noran spectrometer (EDS). To determine the average composition of the specimen, the powders were applied on a graphite conductive tape suitable for high vacuum to obtain a flat layer. The analysis was performed in $250 \times 250 \mu \mathrm{m}$ area three times in various parts of the samples. Presented results were calculated as an average value from the measurements.

\section{Results and discussion}

The XRD patterns of europium doped samples obtained before and after the reduction process are shown in Fig. 4 . As it can be seen in Fig. 4, regardless of the difference in $\mathrm{Y} / \mathrm{Ca}$ concentration ratio, the obtained materials are characterized by the pure phase of $\mathrm{Ca}_{9} \mathrm{Y}\left(\mathrm{PO}_{4}\right)_{7}$ (PDF card no. 00-046-0402). The diffraction patterns do not possess signals from additional, impurity 

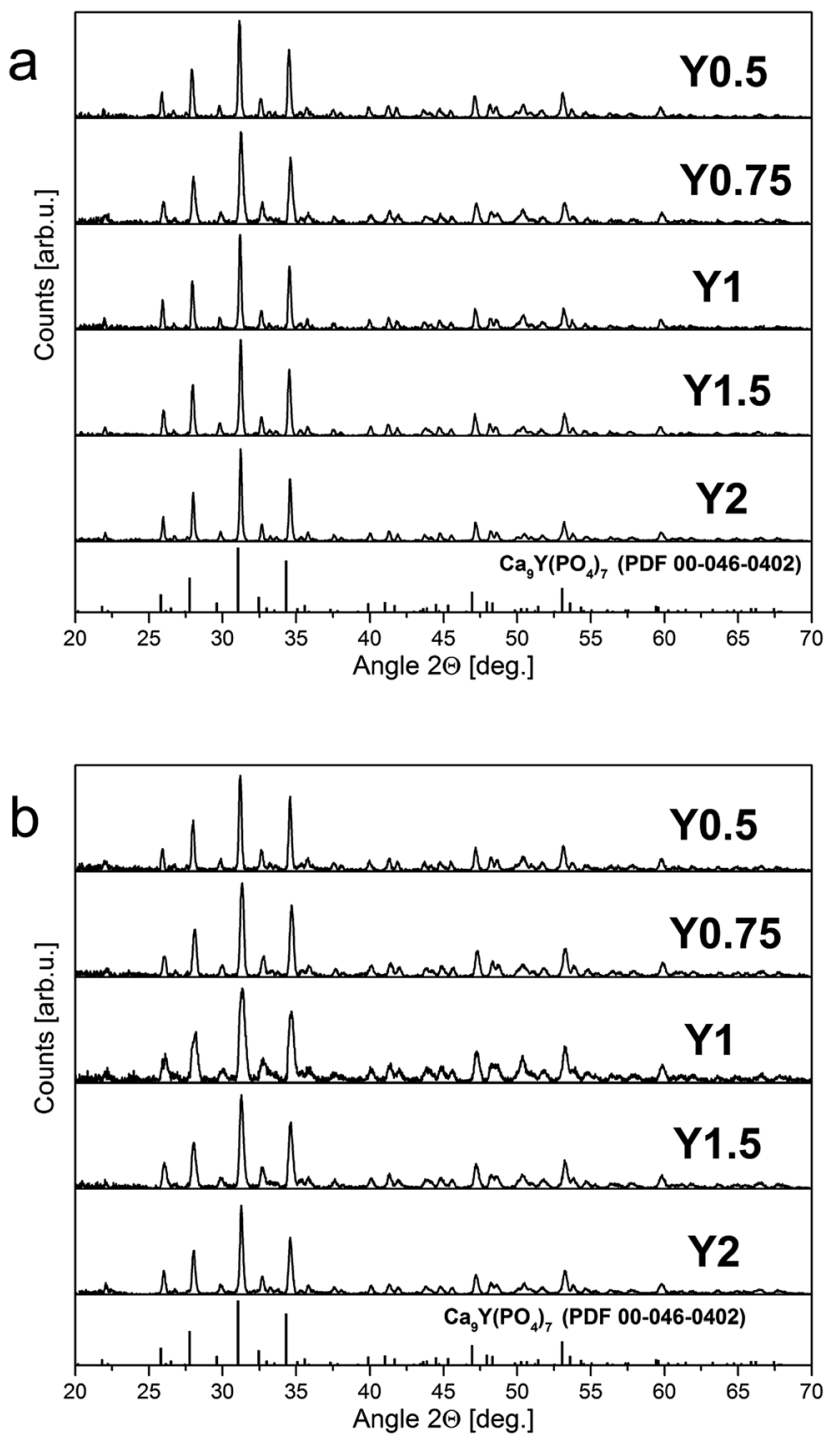

Fig. 4 XRD patterns of samples obtained before (a) and after (b) reduction.

phases. Moreover, the introduction of europium ions or the changes of $\mathrm{Y} / \mathrm{Ca}$ ratio do not cause any significant alteration to the host structure. After the reduction process the phase composition or the structure of the materials is not changed.

Fig. 5 shows the XRD pattern of Y1 sample with the two PDF standards: PDF 00-046-0402 for $\mathrm{Ca}_{9} \mathrm{Y}\left(\mathrm{PO}_{4}\right)_{7}$ and PDF 04-0142292 for $\mathrm{Ca}_{3}\left(\mathrm{PO}_{4}\right)_{2}$. As mentioned previously, the crystallographic structure of $\mathrm{Ca}_{9} \mathrm{Y}\left(\mathrm{PO}_{4}\right)_{7}$ is isostructural to the $\mathrm{Ca}_{3}\left(\mathrm{PO}_{4}\right)_{2}$ and the XRD signals of both phases are identical. Thus, in this case, the XRD method is not sufficient to distinguish these two members of the whitlockite family. To confirm the incorporation of yttrium into the material lattice, the elemental analysis was performed. Table 1 presents the EDX results for the series of materials obtained after the reduction process. As it can be seen, the materials contain the yttrium ions and the concentration of $\mathrm{Y}^{3+}$ increases in order from Y0.5 to Y2. However, in all cases the real concentration is approximately two times lower than assumed. The presence of yttrium ions and the absence of

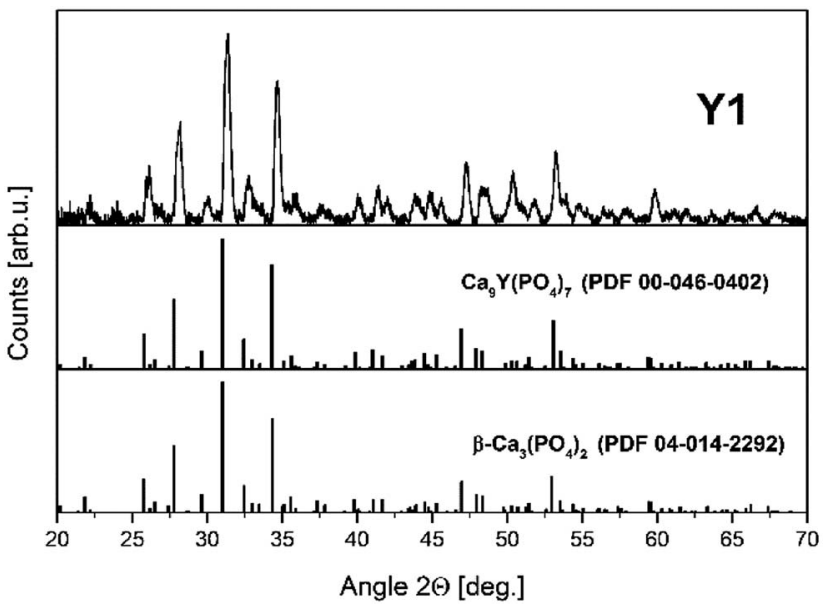

Fig. 5 XRD pattern of $\mathrm{Y} 1$ sample with $\mathrm{Ca}_{9} \mathrm{Y}\left(\mathrm{PO}_{4}\right)_{7}$ and $\mathrm{Ca}_{3}\left(\mathrm{PO}_{4}\right)_{2} \mathrm{PDF}$ standards.

Table 1 Nominal and achieved concentration of $\mathrm{Y}^{3+}$

\begin{tabular}{lllllr}
\hline & \multicolumn{2}{c}{ Nominal atomic\% } & & \multicolumn{2}{l}{$\begin{array}{l}\text { Experimental } \\
\text { atomic\% }\end{array}$} \\
\cline { 2 - 3 } \cline { 5 - 6 } Sample & Ca & Y & & Ca & Y \\
\hline Y0.5 & 95.0 & 5.0 & & 97.3 & 2.7 \\
Y0.75 & 92.5 & 7.5 & 94.8 & 5.2 \\
Y1 & 89.9 & 10.1 & & 94.3 & 5.7 \\
Y1.5 & 84.9 & 15.1 & 86.7 & 13.4 \\
Y2 & 79.9 & 20.1 & 82.1 & 17.9 \\
& & & & &
\end{tabular}

any additional crystal phases of yttrium in the obtained materials confirm that the yttrium ions are incorporated into the crystal lattice.

\section{Optical properties}

The normalized, partial photoluminescence excitation (PLE) and photoluminescence (PL) spectra obtained at room temperature for the $\mathrm{Ca}_{9} \mathrm{Y}\left(\mathrm{PO}_{4}\right)_{7}: \mathrm{Eu}^{3+}$ system with different $\mathrm{Y} / \mathrm{Ca}$ ratios (Y0.5; Y0.75; Y1; Y1.5; Y2) are presented in Fig. 6. PLE spectra are shown in narrow spectral region between 390 and $405 \mathrm{~nm}$ to reveal the differences between the individual spectra. PL spectra of materials obtained after the first step of the synthesis under excitation at $393 \mathrm{~nm}$ and $394 \mathrm{~nm}$ consist of narrow lines, which correspond to the ${ }^{5} \mathrm{D}_{0} \rightarrow{ }^{7} \mathrm{~F}_{J}(J=1,2,3,4)$ transitions in $\mathrm{Eu}^{3+}$ ion. In the case of Y0.5 and Y0.75 materials, the emission spectra do not depend on the excitation wavelength (Fig. 6a and b). For the stoichiometric material (Y1) and materials with the excess of yttrium (Y1.5 and Y2), it is observed that PL spectra depend on the excitation wavelength. Under $393 \mathrm{~nm}$ excitation, it is observed that the emission spectra are identical as the ones obtained for Y0.5 and Y0.75 (Fig. 6c), whereas under $394 \mathrm{~nm}$ excitation, the emission spectral shapes are clearly different from the ones obtained with $393 \mathrm{~nm}$ excitation. The PL spectra under excitation at $394 \mathrm{~nm}$ are characterized by higher intensity of magnetic dipole transition ${ }^{5} \mathrm{D}_{0} \rightarrow$ 


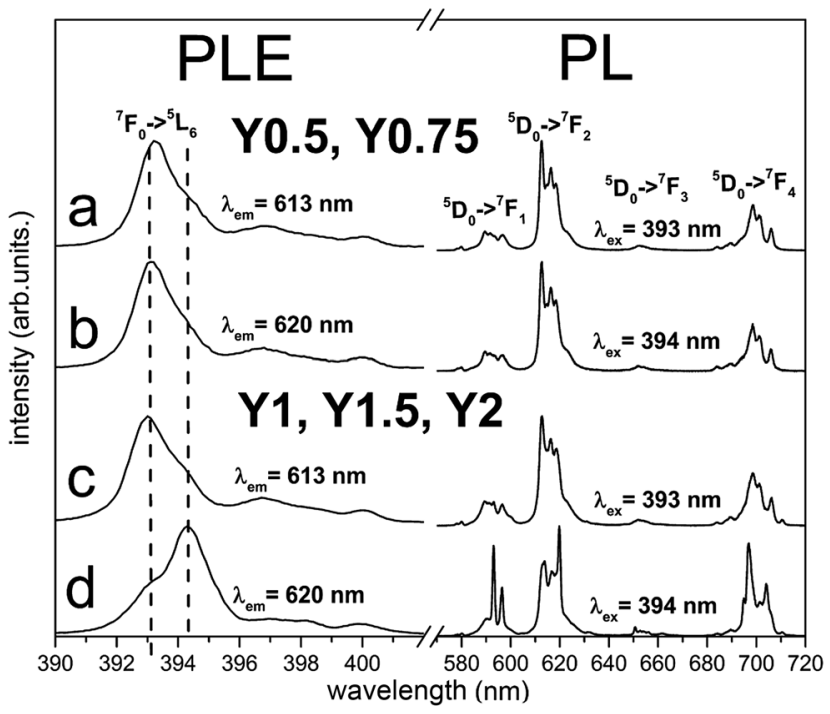

Fig. $6 \mathrm{PL}$ and partial PLE spectra of $\mathrm{Ca}_{9} \mathrm{Y}\left(\mathrm{PO}_{4}\right)_{7}: \mathrm{Eu}^{3+}$ measured at RT before reduction. PLE spectra are recorded monitoring at $613 \mathrm{~nm}$ and $620 \mathrm{~nm}$ wavelength for all samples. The emission spectra were collected under excitation at $393 \mathrm{~nm}$ and $394 \mathrm{~nm}$ for all samples.

${ }^{7} \mathrm{~F}_{1}$ and electric dipole transition ${ }^{5} \mathrm{D}_{0} \rightarrow{ }^{7} \mathrm{~F}_{4}$ than the respective ones obtained under $393 \mathrm{~nm}$ excitation (Fig. 6d). It is worth noting that emission related to the $\mathrm{Eu}^{2+}$ was not observed in the investigated samples.

The PLE spectra for all samples were recorded monitoring luminescence at $613 \mathrm{~nm}$ (Fig. 6a and c) and $620 \mathrm{~nm}$ (Fig. 6b and d) and the excitation line shown on Fig. 6 corresponds to ${ }^{7} \mathrm{~F}_{0} \rightarrow$ ${ }^{5} \mathrm{~L}_{6}$ transition. The most intensive lines seen in PLE spectra have peaks at $393 \mathrm{~nm}$ and $394 \mathrm{~nm}$. It can be noticed that the relative intensities of these lines depend on the monitored emission wavelength and Y/Ca concentration. For Y0.5 and Y0.75, the PLE spectra do not depend on the observation wavelength and the ${ }^{7} \mathrm{~F}_{0} \rightarrow{ }^{5} \mathrm{~L}_{6}$ line is seen at $393 \mathrm{~nm}$. In the case of $\mathrm{Y} 1, \mathrm{Y} 1.5$ and $\mathrm{Y} 2$ different excitation spectra were obtained by monitoring 613 and $620 \mathrm{~nm}$ luminescence. With observation at $613 \mathrm{~nm}$, the excitation line attributed to the ${ }^{7} \mathrm{~F}_{0} \rightarrow{ }^{5} \mathrm{~L}_{6}$ transition is seen at $393 \mathrm{~nm}$, while by monitoring at $620 \mathrm{~nm}$, the line is observed at $394 \mathrm{~nm}$. These spectroscopic features provide evidence that in the case of Y1, Y1.5 and Y2 samples, there is an additional center of $\mathrm{Eu}^{3+}$ which is not observed for samples with deficiency of yttrium (Y0.5 and Y0.75). The ratio of emission intensities attributed to the ${ }^{5} \mathrm{D}_{0} \rightarrow{ }^{7} \mathrm{~F}_{2}$ and the ${ }^{5} \mathrm{D}_{0} \rightarrow{ }^{7} \mathrm{~F}_{1}$ transitions, denoted as asymmetric ratio, is used as a measure for the asymmetry of $\mathrm{Eu}^{3+}$ centers in phosphors. For the $\mathrm{Eu}^{3+}$ center excited with $393 \mathrm{~nm}$, the asymmetric ratio is equal to 6 , while for $\mathrm{Eu}^{3+}$ center excited with $394 \mathrm{~nm}$ this ratio diminishes to about 1.5. This leads to the conclusion that $\mathrm{Eu}^{3+}$ ions excited with $394 \mathrm{~nm}$ occupy the sites in $\mathrm{Ca}_{9} \mathrm{Y}\left(\mathrm{PO}_{4}\right)_{7}$ with a higher inversion symmetry than the ones excited with $393 \mathrm{~nm}$. More distorted sites are attributed to $\mathrm{Eu}^{3+}$ replacing divalent $\mathrm{Ca}^{2+}$ sites with a triclinic $C_{1}$ point group. The sites with higher overall symmetry were attributed to $\mathrm{Eu}^{3+}$ replacing $\mathrm{Y}^{3+}$ sites with a trigonal $C_{3}$ point group.

According to the Tanner work ${ }^{28}$ where the theoretically allowed transition lines of ${ }^{5} \mathrm{D}_{0} \rightarrow{ }^{7} \mathrm{~F}_{J}$ of $\mathrm{Eu}^{3+}$ ions at certain point symmetry groups are present, in our case the 3 peaks of ${ }^{5} \mathrm{D}_{0} \rightarrow{ }^{7} \mathrm{~F}_{1}$, 5 peaks of ${ }^{5} \mathrm{D}_{0} \rightarrow{ }^{7} \mathrm{~F}_{2}$ and 9 peaks of ${ }^{5} \mathrm{D}_{0} \rightarrow{ }^{7} \mathrm{~F}_{4}$ transitions should be observed in the spectra of $\mathrm{Eu}^{3+}$ occupying the sites with $C_{1}$ symmetry, while in the sites of $C_{3}$ symmetry only 2 peaks of ${ }^{5} \mathrm{D}_{0} \rightarrow{ }^{7} \mathrm{~F}_{1}, 3$ peaks of ${ }^{5} \mathrm{D}_{0} \rightarrow{ }^{7} \mathrm{~F}_{2}$ and 6 peaks of ${ }^{5} \mathrm{D}_{0} \rightarrow{ }^{7} \mathrm{~F}_{4}$ transitions should be present. As it can be seen in Fig. 6, the aforementioned splitting is observed only in the emission spectra of $\mathrm{Eu}^{3+}$ excited at $394 \mathrm{~nm}$ for the Y1, Y1.5, Y2 materials. In this case, the $394 \mathrm{~nm}$ excites mainly $\mathrm{Eu}^{3+}$ ions that occupy sites with $C_{3}$ symmetry. In the case of $\mathrm{Eu}^{3+}$ incorporated into the sites with $C_{1}$ symmetry, the situation is much more complicated due to the presence of three deferent $C_{1}$ sites that are available for $\mathrm{Eu}^{3+}$ substitution. These sites are present in all materials and the $\mathrm{Eu}^{3+}$ luminescence cannot be easily distinguished among the sites.

Therefore considering the spectra presented in Fig. 6, one can conclude that when there is a deficiency of yttrium (the case of Y0.5 and Y0.75), $\mathrm{Eu}^{3+}$ ions replace almost only divalent $\mathrm{Ca}^{2+}$ sites, while for the stoichiometric material (Y1) and materials with the excess amount of yttrium ( $\mathrm{Y} 1.5$ and $\mathrm{Y} 2), \mathrm{Eu}^{3+}$ ions occupy, besides the $\mathrm{Ca}^{2+}$ sites, also $\mathrm{Y}^{3+}$ sites.

Another approach to study the number and distortions symmetry of $\mathrm{Eu}^{3+}$ centers is to analyze $\mathrm{Eu}^{3+}$ time-resolved luminescence spectra. This technique was used for the samples obtained before the reduction and with both: deficiency (Y0.5) and excess (Y2) of yttrium. The spectra were measured under $290 \mathrm{~nm}$ excitation wavelength. This excitation wavelength corresponds to the charge transfer transition from the oxygen anion to the empty state of $4 \mathrm{f}^{7}$ of $\mathrm{Eu}^{3+}$ and excites $\mathrm{Eu}^{3+}$ incorporated in the both sites simultaneously. ${ }^{14}$ This excitation was used because there was no possibility to use $393 \mathrm{~nm}$ and $394 \mathrm{~nm}$ excitation wavelength which can be used to excite $\mathrm{Eu}^{3+}$ centers independently.

The time-resolved measurement technique is very useful, because one can observe changes of the emission spectrum shape in time. ${ }^{22}$ The time-resolved luminescence spectra obtained under $290 \mathrm{~nm}$ excitation and for acquisition times: 0-3 ms (solid curves) and 7-10 ms (dotted curves) for Y0.5 and Y2 samples are presented in Fig. 7a and b, respectively. In the case of Y0.5, the shape of the emission profile and the intensity ratio of the individual lines do not change significantly in time. Decay curves of Y0.5 monitoring luminescence at different wavelengths with the spectral width of $2 \mathrm{~nm}\left(\lambda_{\text {obs }}=593 \mathrm{~nm}\right.$, $612 \mathrm{~nm}$ and $696 \mathrm{~nm}$ ) are plotted in Fig. 8a. All curves are single exponential and, to obtain decay times, single exponential functions were fitted. The decay profiles are plotted along with the calculated decay times. Taking into account the fact that the emission profile does not change in time significantly and that the decay times with a measurement error of monitoring luminescence at different wavelengths are equal, we can conclude and confirm the existence of a single $\mathrm{Eu}^{3+}$ site in Y0.5 sample. A different situation is seen for Y2 sample. In the case of Y2, the intensity ratio of the individual lines changes in time, for $0-3 \mathrm{~ms}$ time acquisition the collected emission spectra are similar to the ones collected for Y0.5, while in 7-10 ms time acquisition the higher intensity magnetic dipole transition ${ }^{5} \mathrm{D}_{0}$ $\rightarrow{ }^{7} \mathrm{~F}_{1}$ and electric dipole transition ${ }^{5} \mathrm{D}_{0} \rightarrow{ }^{7} \mathrm{~F}_{4}$ are observed 

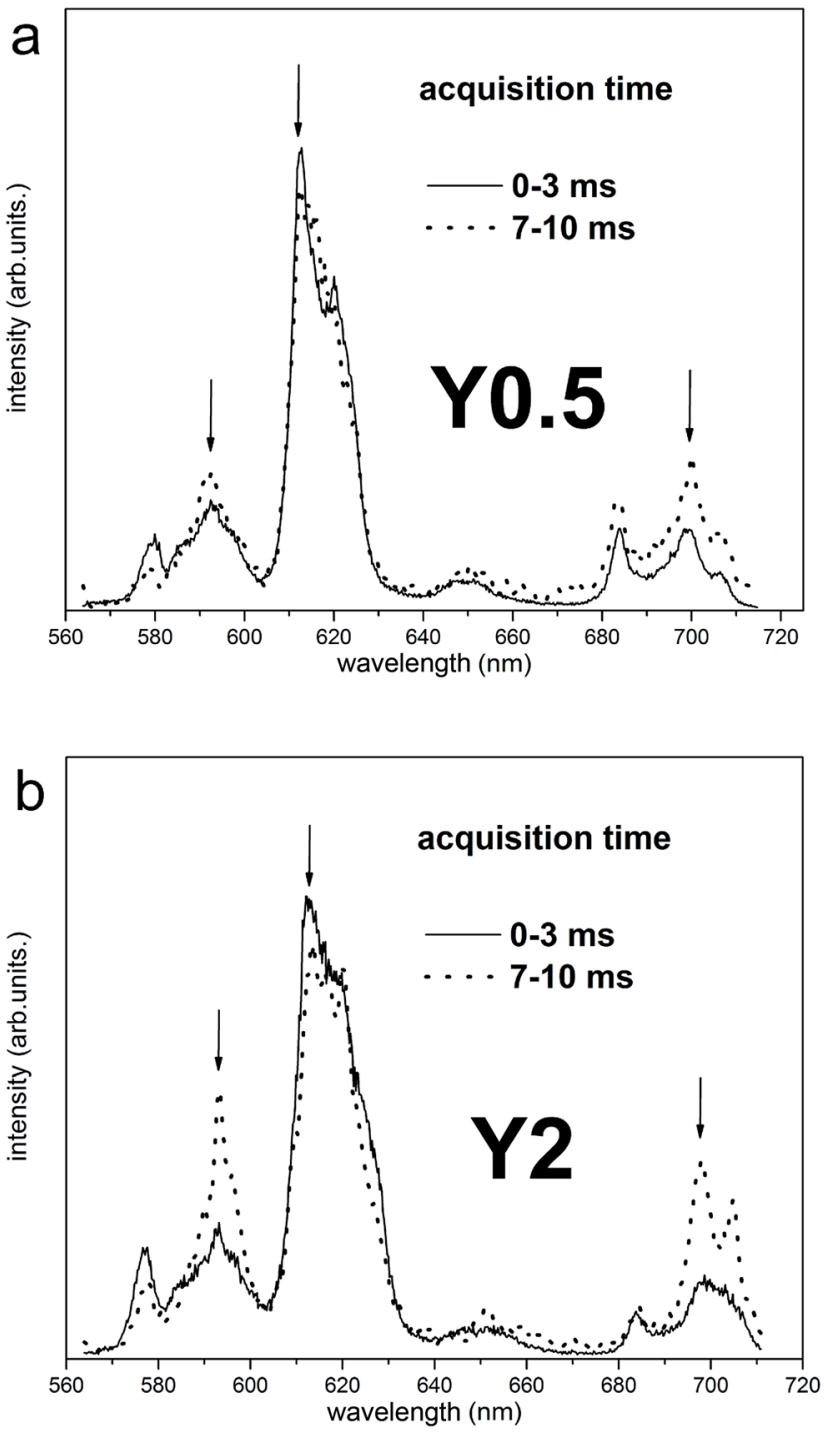

Fig. 7 Time-resolved luminescence spectra for Y0.5:0.05 $\mathrm{Eu}^{3+}$ (a) and Y2:0.05 $\mathrm{Eu}^{3+}$ (b) excited with wavelength $290 \mathrm{~nm}$ for two different acquisition time.

(Fig. 7b). A similar spectrum to the ones collected in 7-10 ms time acquisition was obtained for Y1, Y1.5 and Y2 samples at $394 \mathrm{~nm}$ steady state excitation (see Fig. 6d). The calculated decay times for Y2 ranges from 1.50 to $1.98 \mathrm{~ms}$ with an error of 0.2 ms monitoring ${ }^{5} \mathrm{D}_{0} \rightarrow{ }^{7} \mathrm{~F}_{1,2,4}$ transitions at 593, 612 and $696 \mathrm{~nm}$ wavelengths. Taking into account the fact that the emission profile changes in time significantly and that the decay times with a measurement error of monitoring luminescence at different wavelengths differs, we can conclude the existence of more than one $\mathrm{Eu}^{3+}$ site in $\mathrm{Y} 2$ sample. As it was discussed above, the more distorted sites are attributed to $\mathrm{Eu}^{3+}$ replacing divalent $\mathrm{Ca}^{2+}$ sites with a $C_{1}$ point group and these sites are expected to have a shorter decay time than the site of $\mathrm{Eu}^{3+}$ replacing $\mathrm{Y}^{3+}$, which is a more symmetrical site.

The normalized emission spectra obtained for the samples after the reduction using excitation wavelength equal to $270 \mathrm{~nm}$ are presented in Fig. 9. The chosen wavelength is justified since
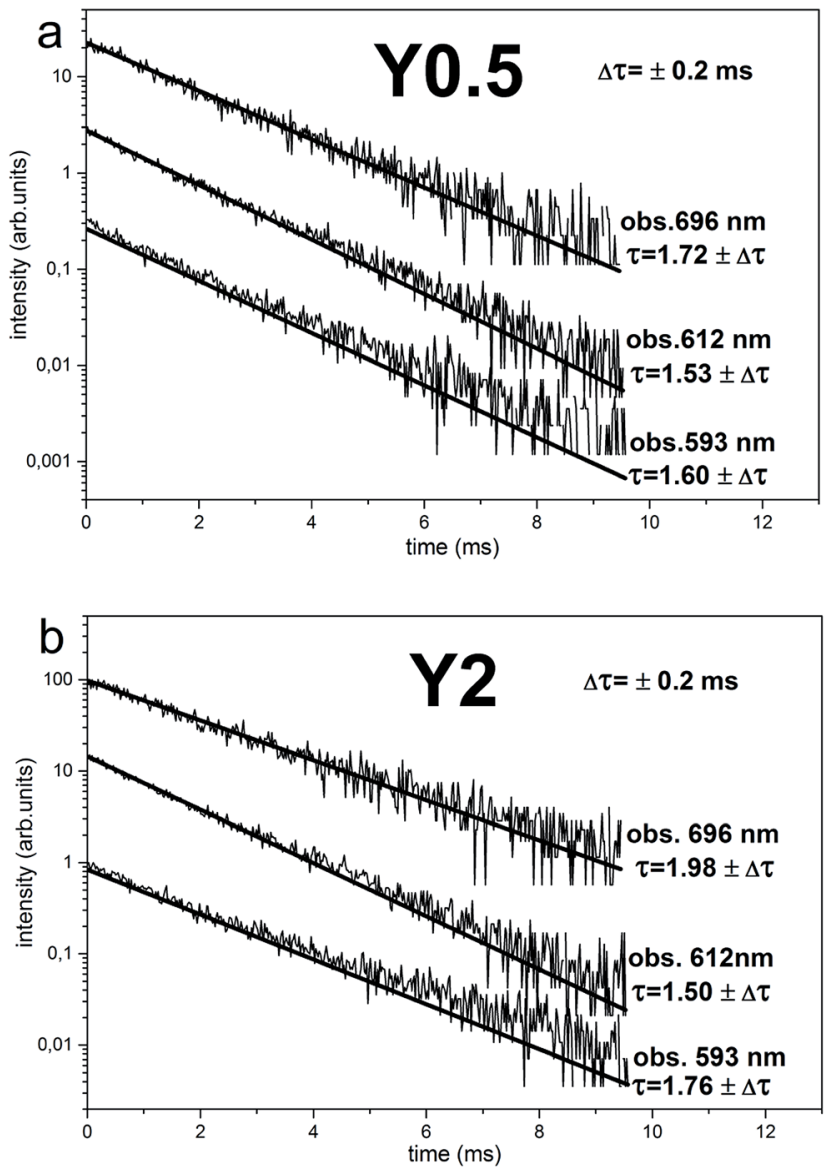

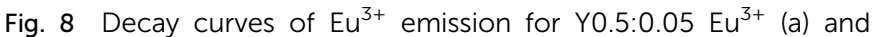
$\mathrm{Y} 2: 0.05 \mathrm{Eu}^{3+}$ (b). The luminescence observed at 593, 612 and $698 \mathrm{~nm}$.

it excites the europium in both oxidation states and corresponds to the intersection of both $\mathrm{Eu}^{2+}$ excitation spectra (Fig. 9) as well as ligand-metal charge transfer band of $\mathrm{Eu}^{3+} \cdot{ }^{\mathbf{1 4}}$ The emission spectra for all samples consist of broad bands related to the $4 \mathrm{f}^{6} 5 \mathrm{~d}^{1} \rightarrow 4 \mathrm{f}^{7}$ transitions occurring in the $\mathrm{Eu}^{2+}$ ions and the narrow emission lines attributed to the ${ }^{5} \mathrm{D}_{0} \rightarrow{ }^{7} \mathrm{~F}_{J}$ transitions in $\mathrm{Eu}^{3+}$. The presence of the latter in all cases indicates that the complete reduction did not occur. However, the intensity of the $\mathrm{Eu}^{3+}$ in comparison to intensity of $\mathrm{Eu}^{2+}$ luminescence diminishes with increasing of the nominal concentration of yttrium in the series of samples. The luminescence of $\mathrm{Eu}^{2+}$ consists of two separated bands: first one with a maximum at $420 \mathrm{~nm}$ and the second with a maximum at $488 \mathrm{~nm}$. The contribution of these two bands to the overall emission spectra changes, depending on the $\mathrm{Y} / \mathrm{Ca}$ ratio in the studied materials. In PL spectrum of the Y0.5 sample, the band with a maximum at $420 \mathrm{~nm}$ dominates. For higher concentration of $\mathrm{Y}$ in the material series (Y0.75, Y1), the contribution of the band at $488 \mathrm{~nm}$ suddenly emerges, and for the materials with an excess of yttrium (Y1.5, Y2), the band at $488 \mathrm{~nm}$ can solely be seen. The Fig. 9 also shows the excitation spectra observed for 430 and $510 \mathrm{~nm}$ wavelengths. As it can be seen the PLE spectra, the line shape depends on the observation wavelength. The excitation spectrum collected for emission, monitored at $430 \mathrm{~nm}$, consists of a single band with a maximum at $268 \mathrm{~nm}$, whereas in the PLE 


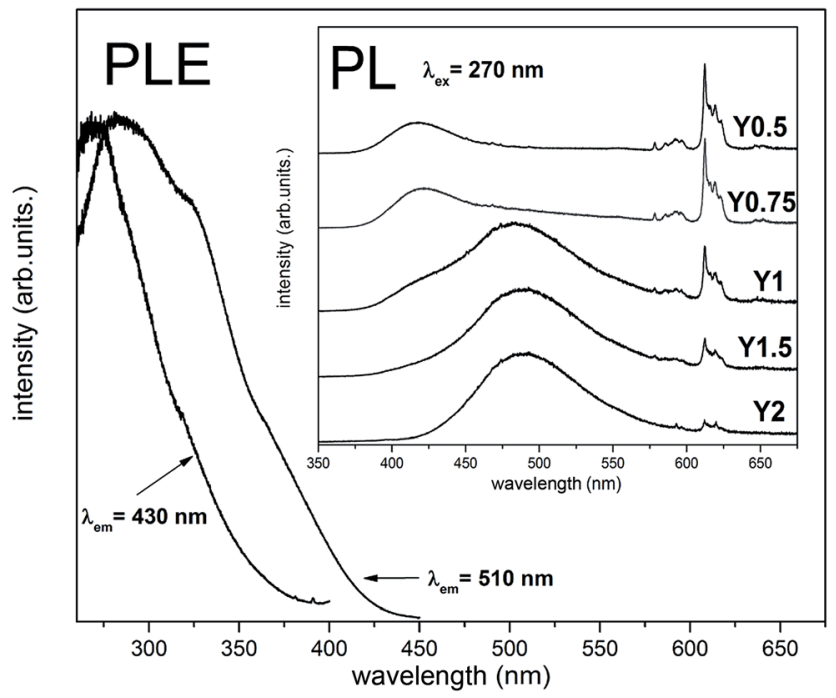

Fig. 9 Excitation spectra monitored at two wavelength corresponding to maxima of luminescence (for materials $Y 0.5$ and $Y 0.75$-obs. $430 \mathrm{~nm}$ and for materials Y1, Y1.5 and Y2-obs. $510 \mathrm{~nm}$ ). Inset: the emission spectra of $\mathrm{Ca}_{9} \mathrm{Y}\left(\mathrm{PO}_{4}\right)_{7}$ after reduction, collected at $\mathrm{RT}$ under excitation at $270 \mathrm{~nm}$ for all samples.

spectrum, monitored at $510 \mathrm{~nm}$, two clear broad bands with maximums at $285 \mathrm{~nm}$ and $325 \mathrm{~nm}$ can be seen.

To analyze the $\mathrm{Eu}^{3+}$ sites remaining after the reduction process, emission spectra under 393 and $394 \mathrm{~nm}$ excitation were also measured and the results are presented in Fig. 10. The emission and excitation spectra of $\mathrm{Eu}^{3+}$ collected for all materials after the reduction have the same profile as respective ones before the reduction, but with lower intensities. Here, as previously, it can be observed that $\mathrm{Eu}^{3+}$ ions incorporated into

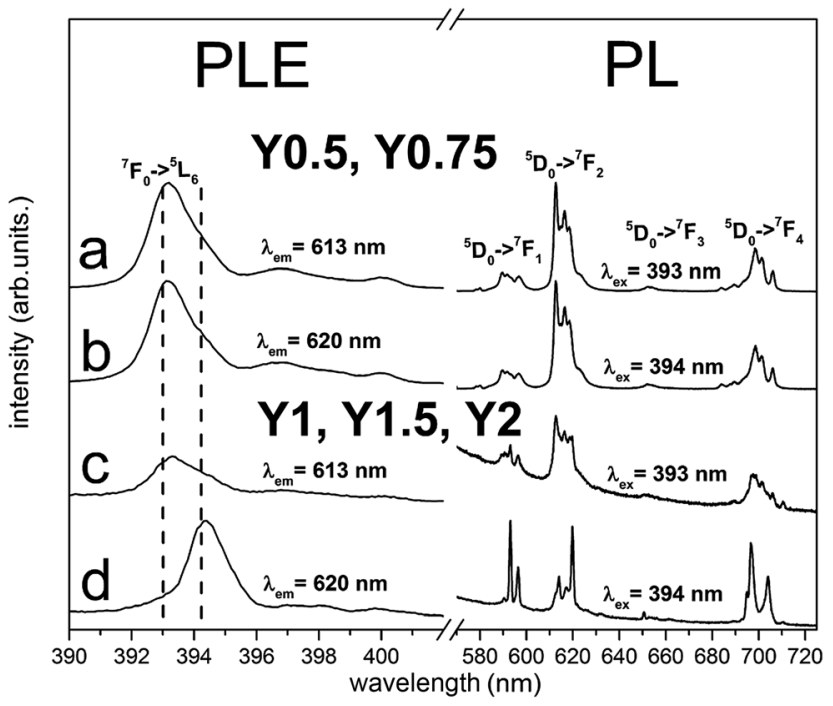

Fig. $10 \mathrm{PL}$ and partial PLE spectra of $\mathrm{Ca} \mathrm{Y}_{9}\left(\mathrm{PO}_{4}\right)_{7}$ :Eu after reduction measured at room temperature. PLE spectra of the emission were recorded at $(613 \mathrm{~nm})$ for all samples and at $620 \mathrm{~nm}$ for $\mathrm{Y} 1-\mathrm{Y} 2$. The emission spectra was collected under excitation at $393 \mathrm{~nm}$ and $394 \mathrm{~nm}$ for all samples. the Y0.5 and Y0.75 samples occupy only one site, as opposed to the two sites in the Y1 and Y2 samples.

Taking into account the criteria for short and long distance charge compensation described in detail in ref. 29 the temperature dependence of $\mathrm{Eu}^{2+} / \mathrm{Eu}^{3+}$ emission intensity ratio was also checked for Y0.5 and Y2 materials. The spectra are presented in Fig. 10a and b. The excitation wavelength was $270 \mathrm{~nm}$ since it allows to excite the $\mathrm{Eu}^{3+}$ trough the charge transfer transition and the $\mathrm{Eu}^{2+}$ through the ${ }^{8} \mathrm{~S}_{7 / 2} \rightarrow 4 \mathrm{f}^{6} 5 \mathrm{~d}$ transition. The mutual relationship of the emission intensity of $\mathrm{Eu}^{3+}$ and $\mathrm{Eu}^{2+}$ depends on the given sample, as discussed above. The emission spectra were scaled to $\mathrm{Eu}^{3+}$ intensity (multiplied or divided by a specific value) to maintain a constant intensity of $\mathrm{Eu}^{3+}$ emission for all temperatures for a given sample. Such a normalization is justified assuming that there are no nonradiative processes that cause $\mathrm{Eu}^{3+}$ emission decrease in measured temperature range $\mathrm{e}^{\mathbf{2 4}}$ and allows to observe changes in $\mathrm{Eu}^{2+}$ intensity. It is seen in Fig. 11 that for both Y0.5 and Y2 samples, the intensity of $\mathrm{Eu}^{2+}$ decreases in respect to $\mathrm{Eu}^{3+}$ when temperature is increased from $10 \mathrm{~K}$ to $400 \mathrm{~K}$. Since the intensity of $\mathrm{Eu}^{2+}$ does not increase when temperature increases (and in fact decreases due to non-radiative processes), we postulate that the compensation of $\mathrm{Eu}^{3+}$ replacing $\mathrm{Ca}^{2+}$ ions takes place at a short distance for both samples.

\section{Mechanisms proposed}

The observed differences in the emission spectra collected for samples obtained after the reduction can be qualitatively explained considering differences in charge compensation mechanisms. The differences arise from the changes in $\mathrm{Y} / \mathrm{Ca}$ concentration ratio in materials series. In the case of materials with deficiency of $\mathrm{Y}^{3+}$ (Y0.5 and Y0.75), the additional positive charge created during the incorporation of $\mathrm{Eu}^{3+}$ ions into the $\mathrm{Ca}^{2+}$ sites (in those materials only $\mathrm{Ca}^{2+}$ sites are occupied by the $\mathrm{Eu}^{3+}$; see discussion of Fig. 5 and 8 ) is compensated by the chemically induced $\mathrm{Ca}_{\mathrm{Y}}^{\prime}$ defects. Moreover, the concentration of $\mathrm{Ca}_{\mathrm{Y}}^{\prime}$ is higher than $\mathrm{Eu}_{\mathrm{Ca}}$ and the excess of the negative charge is compensated by the e.g. oxygen vacancies $\left(\mathrm{V}_{\mathrm{O}}\right)$. Generally, during a reduction process, the gaseous hydrogen, considered as a reducing agent, creates additional oxygen vacancies $\left(\ddot{V_{\mathrm{O}}}\right)$ on the surface of the material particles. ${ }^{30}$ Because the charge compensation in the materials has a local character (short distance compensation), the reduction of $\mathrm{Eu}^{3+}$ to $\mathrm{Eu}^{2+}$ will occur, when the compensation defect of $\mathrm{Eu}_{\mathrm{Ca}}$ is locally eliminated. The $\mathrm{V}_{\mathrm{O}}$ created on the surface during the reduction cannot cause the elimination of $\mathrm{Ca}_{\mathrm{Y}}^{\prime}$ from the surroundings of $\mathrm{Eu}^{3+}$ and for the reduction of the europium ion, the created oxygen vacancy has to be moved from the surface to the vicinity of the $\mathrm{Eu}^{3+}$ and $\mathrm{Ca}_{\mathrm{Y}}^{\prime}$. The situation described above is presented in Fig. 12. This kind of compensation mechanism changes the local environment of $\mathrm{Eu}^{2+}$ center, because one oxygen anion is removed from the vicinity of a reduced europium ion. The emission occurring from this luminescent center is strongly shifted to the blue region in comparison to the other $\mathrm{Eu}^{2+}$ site observed in $\mathrm{Ca}_{9} \mathrm{Y}\left(\mathrm{PO}_{4}\right)_{7}$. The maximum of $\mathrm{Eu}^{2+}$ appears at $420 \mathrm{~nm}$. Such an effect has been observed by Fang et al. ${ }^{31}$ in 

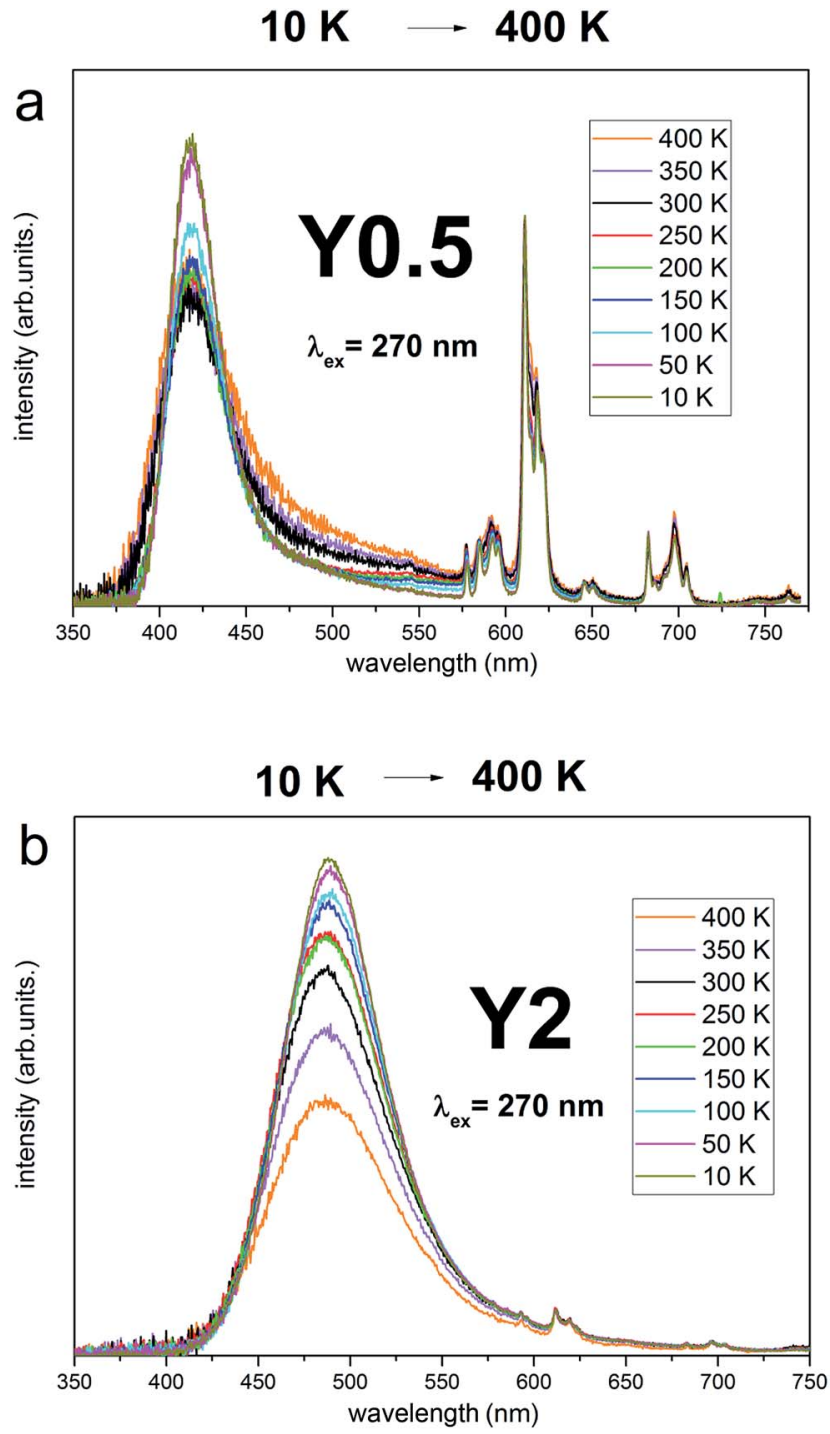

Fig. 11 Luminescence spectra of $\mathrm{Y} 0.5: \mathrm{Eu}^{2+}, \mathrm{Eu}^{3+}$ (a) and $\mathrm{Y} 2: \mathrm{Eu}^{2+}, \mathrm{Eu}^{3+}$ (b) at different temperature under pulsed excitation with $270 \mathrm{~nm}$.

$\mathrm{BaMgSiO}_{4}: \mathrm{Eu}$ and has been attributed to the creation of oxygen vacancy in the first coordination sphere of the europium ion. It is worth noting that the emission of $\mathrm{Eu}^{2+}$ with a maximum at
$420 \mathrm{~nm}$ is typical for europium doped $\mathrm{Ca}_{3}\left(\mathrm{PO}_{4}\right)_{2}$ in rhombohedral form. ${ }^{32,33}$ Thus, the explanation can be the presence of a local crystal domain: e.g. similar symmetry and coordination number of $\mathrm{Eu}^{2+}$ as in the case of $\mathrm{Ca}_{3}\left(\mathrm{PO}_{4}\right)_{2}$. This situation is achieved after the removal of the oxygen anion from the vicinity of europium in the samples with an excess of calcium.

In the studied phosphates, the oxygen ions are a part of phosphorus tetrahedrons, in which elements are bonded with partially covalent bonds. For this reason, the energy necessary for migration of oxygen vacancies, $\mathrm{V}_{\mathrm{O}}$, is relatively high (compared to e.g. calcium vacancies, $\mathrm{V}_{\mathrm{Ca}}^{\prime \prime}$ ). It means that via the proposed compensation mechanism, only a small part of $\mathrm{Eu}^{3+}$ ions (mostly located on the surface) are reduced during the process and intense emission lines of $\mathrm{Eu}^{3+}$ are observed in the spectra (Fig. 9).

A different situation is observed in the case of materials with an excess of $\mathrm{Y}^{3+}$ (Y1.5 and $\left.\mathrm{Y} 2\right)$. Here, the $\mathrm{Eu}^{3+}$ ions are incorporated in $\mathrm{Ca}^{2+}$ and $\mathrm{Y}^{3+}$ sites. The $\mathrm{Eu}_{\mathrm{Y}}^{\times}$impurity does not need compensation due to the same oxidation state of $\mathrm{Eu}^{3+}$ and $\mathrm{Y}^{3+}$, while the additional charge of $\mathrm{Eu}_{\mathrm{Ca}} \cdot$ defects is compensated by the naturally created cation vacancies (e.g. $\left.\mathrm{V}_{\mathrm{Ca}}^{\prime \prime}\right)$. Moreover, in the Y1.5 and Y2 materials, chemically induced, positively charged $\mathrm{Y}_{\mathrm{Ca}}$ defects are also compensated by the cation vacancies. During the reduction process, the $\mathrm{V}_{\mathrm{O}}$. defects are created in the same way as described previously. Due to the short distance charge compensation, the reduction of $\mathrm{Eu}^{3+}$ will occur if $\mathrm{Eu}_{\mathrm{Ca}}$ compensating agent $\left(\mathrm{V}_{\mathrm{Ca}}^{\prime \prime}\right)$ is eliminated. Due to the difference in the type of calcium and oxygen bonding with the nearest neighbors, it is expected that the energy necessary for migration of $\mathrm{V}_{\mathrm{Ca}}^{\prime \prime}$ is much smaller than in the case of the $\mathrm{V}_{\mathrm{O}}^{.}$defects. From the energy difference, it stems that the migration of calcium vacancies to the surface is much more probable than the migration of oxygen vacancies to the bulk crystal to compensate each other. ${ }^{30}$ Fig. 13 shows the scheme of the described situation. This mechanism does not change the local environment of the reduced europium ions and the luminescence of $\mathrm{Eu}^{2+}$ occurs with a maximum of the emission band located at $488 \mathrm{~nm} .{ }^{24}$ Due to the high migration rate of $\mathrm{V}_{\mathrm{Ca}}^{\prime \prime}$, all $\mathrm{Eu}^{3+}$ ions compensated with the calcium vacancies are reduced and the $\mathrm{Eu}^{2+}$ luminescence is relatively intense. However, a part of the europium ions is incorporated into the yttrium sites without compensation defects. It suggests that the luminescence of
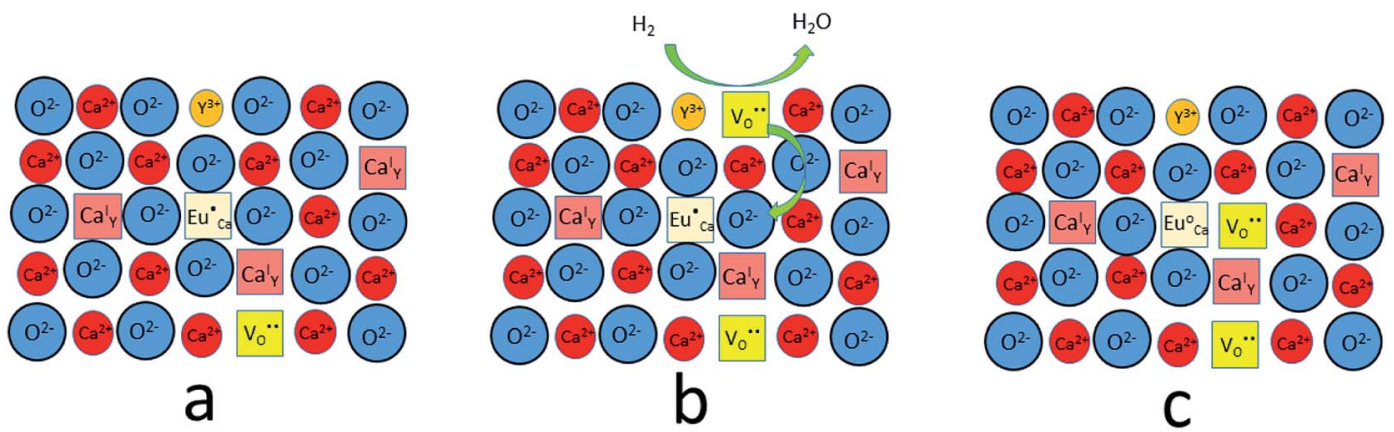

Fig. 12 A scheme of the compensation mechanism occurred in deficiency of $\mathrm{Y}^{3+}$; (a) defects created after synthesis in air; (b) reduction process; (c) distribution of defects after reduction process. 

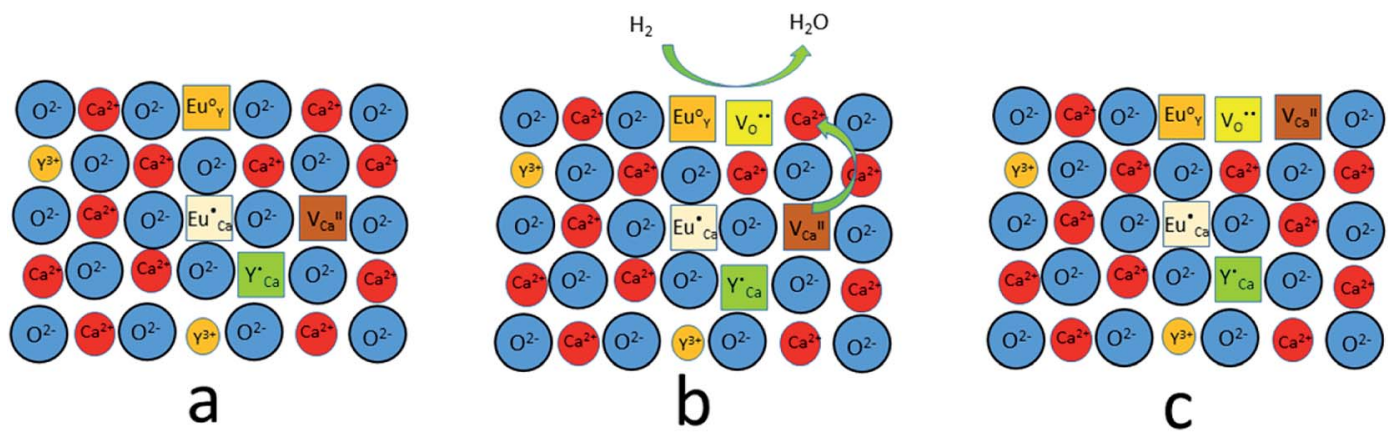

Fig. 13 A scheme of the compensation mechanism occurred in excess of $\mathrm{Y}^{3+}$; (a) defects created after synthesis in air; (b) reduction process; (c) distribution of defects after reduction process.

unreduced $\mathrm{Eu}^{3+}$ ions observed in the emission spectra (Fig. 10) mostly originates from the $\mathrm{Eu}_{\mathrm{Y}}^{\times}$luminescent centers. However, it is assumed that both compensation mechanisms are present in all materials, depending on the randomly occurring distribution of $\mathrm{Eu}^{3+}$ compensating defects. It should be emphasized that the probability of encountering a given compensation mechanism depends on the $\mathrm{Y} / \mathrm{Ca}$ concentration ratio. For the materials with deficiency of $\mathrm{Y}^{3+}$, the mechanism that includes $\mathrm{V}_{\mathrm{O}}$ migration is more probable and in the case of the materials with the excess of $\mathrm{Y}^{3+}$, a more probable mechanism involves migration of $\mathrm{V}_{\mathrm{Ca}}^{\prime \prime}$ defects. For the stoichiometric material (Y1), both of them are almost equally probable.

\section{Conclusions}

The series of luminescent materials based on $\mathrm{Ca}_{9} \mathrm{Y}_{(}\left(\mathrm{PO}_{4}\right)_{7}$ matrix with different $\mathrm{Y} / \mathrm{Ca}$ concentration ratios were obtained in order to study the influence of charge compensation defects on the luminescence of europium ions incorporated into the matrix. Depending on the value of the ratio, different defects are created to compensate the additional positive charge of $\mathrm{Eu}_{\mathrm{Ca}}$. For the materials with the deficiency of $\mathrm{Y}^{3+}, \mathrm{Ca}_{\mathrm{Y}}^{\prime}$ are mainly created, while for the materials with the excess of $\mathrm{Y}^{3+}$, the main defects are $\mathrm{V}_{\mathrm{Ca}}^{\prime \prime}$. It was assumed that both of the defects have different migration rates. The differences in the luminescence of $\mathrm{Eu}^{2+}$ observed in the series of materials were attributed to the differences in the defects migration rates. Moreover, it has been shown that the presence of $\mathrm{Eu}^{2+}$ emission band with a maximum at $420 \mathrm{~nm}$ observed for the materials with the deficiency of $\mathrm{Y}^{3+}$ is a result of changes in the local environment of $\mathrm{Eu}^{2+}$ center, because one oxygen anion is removed from the vicinity of the reduced europium ion.

\section{Acknowledgements}

This research is supported by the National Science Centre, Poland, agreement number: UMO 2014/13/D/ST3/04032. The authors would like to thank Prof. Adriana Zaleska for the opportunity to perform the materials syntheses and M. Sc. Michał Nischk for his support during the syntheses. D. M. and M. G. have been supported by the National Centre for Research and Development by grant TAZOLED, PBS3/A5/48/2015.

\section{Notes and references}

1 Q. Dong, Y. Wang, Z. Wang, X. Yu and B. Liu, J. Phys. Chem. C, 2010, 114, 9245-9250.

2 A. A. Reddy, S. Das, S. Ahmad, S. S. Babu, J. M. F. Ferreirab and G. V. Prakasha, RSC Adv., 2012, 2, 8768-8776.

3 C. $\mathrm{Wu}, \mathrm{K}$. Chen, C. Lee, T. Chen and B. Cheng, Chem. Mater., 2007, 19, 3278-3285.

4 G. Dong, H. Ma, Y. Liu, Z. Yang and Q. Liu, Opt. Commun., 2012, 285, 4097-4101.

5 M. Xie, Y. Li and R. Li, J. Lumin., 2013, 136, 303-306.

6 V. B. Taxak, S. Dayawati and S. P. Khatkar, Curr. Appl. Phys., 2013, 13, 594-598.

7 K. N. Shinde, S. J. Dhoble, H. C. Swart and K. Park, Springer Series in Materials Science, vol. 174, 2012.

8 S. Du, D. Wang, Y. Wang, S. Xin, Q. Qiang and X. Ma, New J. Chem., 2015, 39, 5605.

9 C.-H. Huang, L. Luo and T.-M. Chen, J. Electrochem. Soc., 2011, 158, 341.

10 H. K. Li, B. K. Yang, B. Moon, Ch. Choi, J. H. Jeong, K. Jang, H. S. Lee and S. S. Yi, Opt. Mater. Express, 2012, 2(4), 443.

11 J. Sun, W. Zhou, Y. Sun and J. Zeng, Opt. Commun., 2013, 296, 84.

12 X. Wu, Y. Liang, R. Chen, M. Liu and Z. Cheng, Mater. Chem. Phys., 2011, 129, 1058.

13 A. Watras, I. Carrasc, R. Pazik, R. J. Wiglusz, F. Piccinelli, M. Bettinelli and P. J. Deren, J. Alloys Compd., 2016, 672, 45.

14 F. Du, Y. Nakai, T. Tsuboi, Y. Huang and H. J. Seo, J. Mater. Chem., 2011, 21, 4669.

15 F. Piccinelli, M. Trevisani, J. R. Plaisier and M. Bettinelli, J. Rare Earths, 2015, 33, 977.

16 A. Lecointre, A. Bessière, B. Viana, R. AïtBenhamou and D. Gourier, Radiat. Meas., 2010, 45, 273.

17 Q. Liu, Y. Liu, Z. Yang, X. Li and Y. Han, Spectrochim. Acta, Part A, 2012, 87, 190.

18 B. Wang, Y. Lin and H. Ju, J. Alloys Compd., 2014, 584, 167.

19 V. N. Golubev and B. I. Lazoryak, Izv. Akad. Nauk SSSR, Neorg. Mater., 1991, 27, 576.

20 Y. Lu, C. H. Huang, T. M. Chen, J. H. Lin, Y. R. Ma, J. L. Chen, C. C. Hsu, C. L. Chen, C. L. Dong and T. S. Chan, Chem. Phys. Lett., 2011, 515, 245.

21 X. Zhang, L. Zhou and M. Gong, Opt. Mater., 2013, 35, 993. 
22 K. Li, Y. Zhang, X. Li, M. Shang, H. Lian and J. Lin, Dalton Trans., 2015, 44, 483.

23 A. Watras, P. J. Deren, R. Pazik and K. Maleszka-Bagińska, Opt. Mater., 2012, 34, 2041.

24 H. Lee, M. Hong, S. Bae, H. Lee, E. Park and K. Kim, J. Mater. Chem., 2003, 13, 2626.

25 M. Puchalska, Y. Gerasymchuk and E. Zych, Opt. Mater., 2010, 32, 1117.

26 R. Pazik, K. Zawisza, A. Watras, K. Malesza-Bagińska, P. Boutinaud, R. Mahiou and P. J. Deren, Mater. Res. Bull., 2013, 48, 337.

27 A. A. Kubicki, P. Bojarski, M. Grinberg, M. Sadownik and B. Kukliński, Opt. Commun., 2006, 263, 275.
28 A. Tanner, Chem. Soc. Rev., 2013, 42, 5090.

29 A. Baran, J. Barzowska, M. Grinberg, S. Mahlik, K. Szczodrowski and Y. Zorenko, Opt. Mater., 2013, 35, 2107.

30 K. Szczodrowski, J. Barzowska, N. Górecka and M. Grinberg, RSC Adv., 2016, 6, 48001.

31 W. Ji, M.-H. Lee, L. Hao, X. Xu, S. Agathopoulos, D. Zheng and C. Fang, Inorg. Chem., 2015, 54, 1556.

32 K. Li, D. Chen, J. Xu, R. Zhang, Y. Yu and Y. Wang, Mater. Res. Bull., 2014, 49, 677.

33 Y.-j. Zhang, Z.-y. Mao, D.-J. Wang and J. Zhao, Mater. Res. Bull., 2015, 67, 1. 